\title{
IL-2 and IFN-gamma and diabetic retinopathy
}

\author{
Viroj Wiwanitkit
}

Received: 31 May 2010 /Accepted: 4 July 2010 /Published online: 21 July 2010

(C) Springer-Verlag 2010

Editor, I read the recent report on IL-2 and IFN-gamma study on rat model with great interest [1]. Johnsen-Soriano et al. concluded that "Immunoregulatory cytokines belonging to the Th-1 group (IL-2 and IFN-gamma) were increased in the retina of experimental diabetic rats [1]" and "the nitrotyrosine formation (as an expression of increased NO production) was significantly elevated in the diabetic retina, supporting the concept of an inflammatory element in the development of diabetic retinopathy [1]." I have some comments on this work. Whether the experimental design is statistically acceptable should be discussed. The exact process that induced the increasing IL-2, IFN-gamma and NO production in the experimented rats is still questionable. Indeed, evidence of no oxidation flux change in retina membrane is reported [2]. The concern on diabetic retinopathy is not limited to the hyperglycemic stage but the control of fluctuation of the blood glucose. An important cause of cellular damage in diabetes is the exothermic energy from fluctuation of blood glucose [3].

\section{References}

1. Johnsen-Soriano S, Sancho-Tello M, Arnal E, Navea A, Cervera E, Bosch-Morell F, Miranda M, Javier Romero F (2010) IL-2 and IFN-gamma in the retina of diabetic rats. Graefes Arch Clin Exp Ophthalmol 248(7):985-990

2. Wiwanitkit V (2007) Oxidation flux change in diabetic retinopathy: does it exist or not? Diabetol Croat 36(3):55-57

3. Wiwanitkit V (2006) Energy consumption for the formation of hemoglobin A1c: a reappraisal and implication on the poorcontrol diabetes mellitus patients. J Diabetes Complicat 20 (6):384-386

\footnotetext{
V. Wiwanitkit $(\bowtie)$

Wiwanitkit House,

Bangkhae, Bangkok 10160, Thailand

e-mail: wviroj@yahoo.com
} 